\title{
APROXIMAÇÕES ENTRE O PROCESSO DE ADAPTAÇÃo DE PIAGET E OS MODOS DE CONVERSÃO DO CONHECIMENTO DE NONAKA \& TAKEUCHI
}

\author{
Marina Ferreira de Castro Wille ${ }^{\mathrm{i}}$ \\ Regina Alves de Morais Marques ${ }^{\text {ii }}$ \\ Helena de Fátima Nunes Silva ${ }^{\text {iii }}$ \\ Tânia Stoltz ${ }^{\text {iv }}$ \\ Verônica Branco ${ }^{\mathrm{v}}$
}

\begin{abstract}
Resumo: O presente artigo relaciona conceitos da teoria de criação do conhecimento organizacional de Nonaka e Takeuchi com conceitos envolvidos no processo de equilibração majorante de Piaget. A pesquisa bibliográfica e exploratória busca relacionar tais teóricos a fim de enriquecer a pesquisa organizacional com contribuições da área educacional e da psicologia. A discussão aponta para uma aproximação entre os modos de conversão do conhecimento de Nonaka e Takeuchi, ou seja, socialização, externalização, combinação e internalização, com elementos envolvidos no processo de equilibração majorante de Piaget, tidos como assimilação, acomodação, conflito cognitivo e adaptação. Conclui-se que os referenciais tratados podem ser compreendidos como embasados em visão construtivista e interacionista.
\end{abstract}

Palavras-chave: Conhecimento organizacional. Nonaka. Takeuchi. Piaget.

\section{PROXIMITIES BETWEEN PIAGET'S ADAPTATION PROCESS AND NONAKA \& TAKEUCHI'S KNOWLEDGE CONVERSION MODES}

\begin{abstract}
This article relates theoretical concepts from Nonaka e Takeuchi's theory of organizational knowledge creation with concepts from Piaget's theory of equilibration. The bibliographical and exploratory research intends to associate both theories in order to enrich the organizational literature with elements from the educational and psychology areas. The discussion points out similarities between the modes of knowledge conversion from Nonaka e Takeuchi and elements involving Piaget's theory of equilibration, such as assimilation, accommodation, cognitive conflict and adaptation. In conclusion, the article demonstrates how the authors may have the same constructivist and interactionist foundation.
\end{abstract}

Keywords: Organizational Knowledge. Nonaka. Takeuchi. Piaget.

\footnotetext{
${ }^{\mathrm{i}}$ Universidade Federal do Paraná. mfcw@hotmail.com

${ }^{i i}$ Universidade Federal do Paraná. re3gina@yahoo.com.br

iii Universidade Federal do Paraná. helenanunes@ufpr.br

${ }^{\text {iv } U n i v e r s i d a d e ~ F e d e r a l ~ d o ~ P a r a n a ́ . ~ t s t o l z @ u f p r . b r ~}$

${ }^{v}$ Universidade Federal do Paraná. veronica branco@hotmail.com
} 


\section{INTRODUCÃO}

O objetivo deste artigo é relacionar conceitos da teoria de Piaget e da teoria de Nonaka e Takeuchi no que se refere à construção do conhecimento e aos modos de conversão propostos pelos últimos autores. Essa ideia surge a partir da identificação da menção a Piaget na obra de Nonaka (1994), em seu artigo intitulado “A Dynamic Theory of Organizational Knowledge Creation". Além dessa, outra obra, organizada por Nonaka e Ichijo (GILBERT, 2007, p. 216-217) também apresenta conceitos piagetianos, confirmando a visão de Pinto (2001), que considera que o núcleo teórico da Teoria de Criação do Conhecimento de Nonaka e Takeuchi é, em parte, formado pela teoria piagetiana. Assim, por meio de uma pesquisa bibliográfica exploratória, serão tratados os modos de conversão do conhecimento entendidos por Nonaka e Takeuchi (1997) como socialização, externalização, combinação e internalização com o processo de equilibração majorante de Piaget (1986), envolvendo os conceitos de assimilação, acomodação, conflito cognitivo e adaptação.

\section{CONSTRUÇÃO DO CONHECIMENTO SEGUNDO NONAKA E TAKEUCHI}

Nonaka e Takeuchi (1997) enfatizam que o processo de criação do conhecimento constitui-se em um modelo dinâmico, que acontece por meio da interação social entre os conhecimentos tácito e explícito. O primeiro tipo de conhecimento - o tácito - é relativo àquilo que é pessoal e específico a um contexto, sendo de difícil verbalização ou expressão, já que é subjetivo. Esse tipo de conhecimento é composto por elementos cognitivos e técnicos. Os elementos cognitivos ajudam o indivíduo a perceber e definir seu mundo por meio de modelos, paradigmas, esquemas, perspectivas, crenças, entre outros. Esses elementos são relativos às imagens da realidade de cada pessoa, que indicam "o que é" e às visões para o futuro referentes ao "que deveria ser". Já os elementos técnicos, referem-se às técnicas e habilidades mais concretas do indivíduo, seu know-how. O conhecimento tácito depende do contexto, já que é criado no presente, não necessitando de ordem ou sequência para existir.

Outro tipo de conhecimento entendido por Nonaka e Takeuchi (1997) é o conhecimento explícito, ou seja, o conhecimento facilmente expressado. Este tipo de conhecimento é objetivo, racional, organizado e sistemático. O conhecimento explícito é baseado no passado e em seus acontecimentos, sendo assim, é sequencial e independente de 
contexto.

A interação entre esses dois tipos de conhecimento é denominada conversão de conhecimento, que ocorre de quatro modos distintos, conforme a Figura 1, e explicados a seguir.

Figura 1 - Espiral do conhecimento

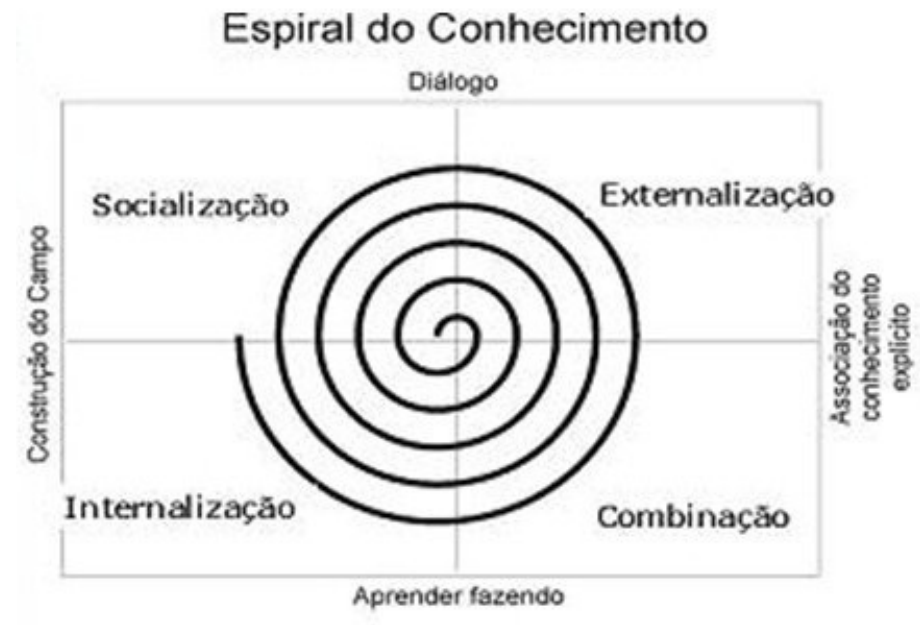

Fonte: Adaptação de Nonaka e Takeuchi (1997)

O início da espiral do conhecimento se dá na socialização, quando há compartilhamento de conhecimento tácito com conhecimento tácito, como, por exemplo, ter dois chefes de cozinha ensinando e aprendendo procedimentos práticos de culinária entre si. O aprendizado não ocorre apenas por meio da verbalização do que está sendo feito, mas também pela observação e experiência da prática.

A partir desse compartilhamento de conhecimento tácito, passa-se para o modo de externalização, entendida como a articulação do conhecimento tácito em conhecimento explícito. Isso significa dizer que o conhecimento tácito deixa de ser subjetivo, passando a ser compreendido e sistematizado de forma a permitir sua codificação e exteriorização, muitas vezes pela escrita, linguagem, analogias, metáforas, entre outros. Os autores ainda entendem que o modo de externalização é o mais crucial e importante para a criação do conhecimento propriamente dito. Isso porque é por meio da externalização que novos conceitos são criados.

Tendo externalizado o conhecimento, o próximo modo é o da combinação, em que se sistematizam os diferentes conjuntos de conhecimento explícito, o que pode ser realizado pela combinação de documentos, conversas, encontros, entre outros. Essa combinação, que pode gerar novas classificações, ordenamentos e categorizações do conhecimento explícito, 
também pode gerar a criação de novos conhecimentos, a exemplo das escolas.

Enfim, para fechar o ciclo e um novo se iniciar, tem-se a internalização, que ocorre ao se incorporar o conhecimento explícito em conhecimento tácito, que pode resultar em modelos mentais ou know-how. Esses quatro modos de conversão de conhecimento ocorrem interativa e ciclicamente, como uma espiral, que tem seu início no modo de socialização passando por todos os outros modos até dar início a outra volta continuamente.

Para Nonaka e Takeuchi (1997) existem cinco condições capacitadoras para se criar o conhecimento na organização. A existência dessas condições em níveis organizacionais propicia a evolução da espiral do conhecimento. A primeira delas é a Intenção, "que é definida como a aspiração de uma organização às suas metas" (NONAKA e TAKEUCHI, 1997, p. 83). Isso significa dizer que as estratégias da empresa devem ser suportadas e devem dar suporte ao processo de criação de conhecimento. Em termos práticos, a intenção pode ser expressa por meio de padrões e estratégias que servem como direcionadores para aquilo que a organização busca. É por meio da intenção que é possível dar valor às informações e aos conhecimentos da organização.

A Autonomia é a segunda condição capacitadora, segundo Nonaka e Takeuchi (1997), e refere-se ao modo de agir dos indivíduos dentro da organização. Para que a espiral do conhecimento possa acontecer adequadamente, deve ser dada a autonomia de ação a cada indivíduo de acordo com suas circunstâncias. Essa relativa falta de rigidez interna promove a automotivação para a criação de novos conhecimentos, na medida em que é mais flexível em seus processos de "adquirir, interpretar e relacionar informações" (NONAKA e TAKEUCHI, 1997, p. 86).

A terceira condição capacitadora é a Flutuação e Caos Criativo, que traz estímulos para o relacionamento e interação organizacionais. Conforme explicado pelos autores, flutuação quer dizer um estado de "ordem desordenada", ou seja, um padrão difícil de se prever, sem se tornar uma desordem total. A flutuação também pode gerar um “'colapso' de rotinas, hábitos ou estruturas cognitivas" que trazem a vantagem de promover questionamentos sobre os pensamentos e atitudes, fazendo com que os indivíduos se voltem à interação social, possibilitando a criação de novos conceitos (NONAKA e TAKEUCHI, 1997, p. 89). Já o caos criativo é descrito como um caos intencional e pode ser gerado a partir da flutuação na organização ou ser propositalmente induzido a fim de obter reflexões mais profundas sobre a resolução de problemas. Essa condição, se aplicada em organizações cujos colaboradores não reflitam sobre suas ações, pode provocar um "caos destrutivo", já que seu 
propósito é levantar questionamentos e promover o surgimento de novos conceitos, soluções e formas de pensar.

Como quarta condição capacitadora, surge a Redundância, que não deve ser entendida como desperdício ou pouca eficiência e eficácia em relação à informação, mas sim como sua superposição intencional. A intenção é compartilhar os mesmos conceitos, ideias e informações advindos de indivíduos diferentes, a fim de promover o compartilhamento de visões diversas e a criação de novos conhecimentos. Além disso, a redundância ajuda os indivíduos a entenderem melhor suas posições hierárquicas na organização, levando-a, assim, a "controlar a direção do pensamento e ação individuais." (NONAKA e TAKEUCHI, 1997, p. 92).

A Variedade de Requisitos é a quinta condição capacitadora que promove a espiral do conhecimento. De acordo com Ashby ${ }^{6}$ (1956 apud NONAKA e TAKEUCHI, 1997, p. 94), "a diversidade interna de uma organização deve corresponder à variedade e à complexidade do ambiente para permitir que ela enfrente os desafios impostos pelo ambiente." Dessa forma, a flexibilização e desburocratização do acesso à informação promovem uma maior variedade de conhecimento de cada indivíduo, tornando-o mais apto a agir de acordo com os eventos ambientais da organização.

Esses cinco capacitadores são os fatores principais envolvidos para possibilitar e potencializar a ocorrência dos modos de conversão do conhecimento (espiral do conhecimento) e serão também tratados na discussão com elementos teóricos piagetianos. Para tanto, apresentam-se a seguir os aspectos da teoria de Piaget a serem trabalhados.

\section{CONSTRUÇÃO DO CONHECIMENTO SEGUNDO JEAN PIAGET}

O suíço e biólogo Jean Piaget (1896 - 1980) dedicou grande parte de sua vida pesquisando temas relacionados à psicologia, à lógica e à metodologia científica. Seus questionamentos eram direcionados ao entendimento da origem da inteligência e do conhecimento, da evolução humana e da racionalidade.

Em contraponto aos modelos de inteligência inata, comuns à sua época, ao estudar o comportamento lógico da criança, Piaget propõe que a inteligência desenvolve-se a partir de construções. Seu entendimento é que o conhecimento se constrói a partir da interação com o

\footnotetext{
${ }^{6}$ ASHBY, W.R. An introduction to cybernetics. London: Chapman \& Hall, 1956.
} 
meio físico e social, por meio da atividade do sujeito. Dessa forma, o surgimento do conhecimento, para Piaget, não pode ser visto como anterior à existência social e nem como uma cópia da realidade.

Conhecer um objeto, conhecer um acontecimento, não é simplesmente olhar para ele e fazer uma cópia ou imagem mental dele. Conhecer um objeto é agir sobre ele. Conhecer é modificar, transformar o objeto e entender o processo dessa transformação, e como uma conseqüência, entender como o objeto é construído. (PIAGET, 1964, p. 177)

Percebe-se, então, que, para Piaget, o processo de aprendizagem não é previsível ou determinado pelo simples contato direto do sujeito com o objeto de conhecimento. De outra forma, depende dos processos de adaptação, que possibilitam a referida apropriação do conhecimento enquanto construção, conforme se pretende revisar a seguir.

Antes de tratar do processo de adaptação, deve-se pontuar, contudo, que o desenvolvimento e a aprendizagem, na obra piagetiana, sempre estão relacionados a estruturas de conhecimento. Tais estruturas ampliam-se gradativamente ao longo do desenvolvimento graças a novas construções cognitivas ao mesmo tempo em que dão suporte às novas aprendizagens. Ao nascer, o ser humano apresenta, somente, as suas estruturas orgânicas e são estas que utiliza para a construção de suas estruturas cognitivas.

As estruturas são sistemas de transformação que se constroem na interação do sujeito com as reações do objeto, sendo que, em cada fase do desenvolvimento, se apresenta com certa totalidade, um tipo de equilíbrio entre suas transformações. Ao mesmo tempo, essas transformações representam o caráter flexível das estruturas, pois se expandem com base nas aquisições anteriores, concorrendo sempre para suprir a necessidade de coerência e organização dos conhecimentos do sujeito. Em outras palavras, pode-se dizer que a estrutura de conhecimento (cujas características diferenciam-se qualitativamente em cada etapa do desenvolvimento) são sistemas de transformação que viabilizam novas aquisições e estas, por sua vez, são enriquecidas por novas conquistas, impulsionando o sujeito a estágios mais avançados do desenvolvimento.

As estruturas estão ligadas ao processo de adaptação de duas maneiras: sendo enriquecidas pelas adaptações e possibilitando-as através dos esquemas. Os esquemas são conjuntos de ações e de coordenação de ações, voltadas para um mesmo fim e com características específicas em cada estágio do desenvolvimento. Os esquemas surgem, portanto, a partir da ação e constituem o que se generaliza a partir desta. Representam a menor unidade do desenvolvimento cognitivo.

Retomemos então o processo de adaptação. Para Piaget (1971), esse processo 
representa a forma de avanço da inteligência humana, em todo percurso do desenvolvimento do sujeito e é resultado da assimilação e da acomodação. Piaget (1986, p.18) afirma que a adaptação representa o equilíbrio entre a assimilação e acomodação, e a ela denomina inteligência. Segundo Teixeira (2008, p. 16), a "adaptação é um sistema autorregulador próprio dos seres vivos". A autora, baseada em Piaget, afirma que é a autorregulação entre o objeto de conhecimento e a estrutura cognitiva do sujeito que desencadeia o desenvolvimento.

A assimilação é, para Piaget $(1971,1978)$, o processo pelo qual o sujeito reconhece e reage a um novo dado do meio externo. Na assimilação, o indivíduo "age sobre os objetos ao seu redor assimilando-os e integrando-os em sua estrutura cognitiva.” (TEIXEIRA, 2008, p. 16). García e Fabregat (1998, p. 85) entendem que a assimilação é a integração de objetos ${ }^{7}$ aos esquemas de ação do indivíduo.

Nesse caso, quanto à aprendizagem e compreensão, pode-se dizer que na assimilação o indivíduo permanece no mesmo nível de conhecimento. Ou seja, a assimilação por si só não transforma, não reorganiza estruturas e, por isso, não faz generalizações; apenas adiciona novas informações aos esquemas desenvolvidos (PIAGET 1971).

A segunda etapa do processo de adaptação é a acomodação, que de acordo com Silva (2008, p. 2), é “a ação do sujeito sobre si mesmo”, pois a acomodação demanda mudança e ajuste de esquemas. Tanto Cohen e Kim (1999) como Nunes (1998) afirmam que a acomodação gera modificações na própria estrutura do sujeito. A partir de Piaget (1971), compreende-se que, nesse processo, o sujeito ajusta novos dados ao seu repertório prévio, estabelece relações, generaliza as novas informações, sendo capaz de aplicá-las em outras situações e, por isso, alterando seu estado inicial.

Percebe-se, então, que os processos de assimilação e acomodação cooperam para um mesmo fim:

...há adaptação a partir do momento em que o organismo se transforma em função
do meio, e que esta variação tenha por consequência um aumento das trocas entre o
meio e organismo que sejam favoráveis à sua conservação (PIAGET, 1971, p. 17).

Pode-se concluir, portanto, que em relação à aprendizagem, o processo de adaptação depende dos processos de assimilação e acomodação (que são como formas de atividade intelectual do sujeito em relação ao objeto de conhecimento), sendo que esses cooperam para mudanças, ajustes e reelaborações na estrutura de conhecimento do indivíduo. Em outras palavras, na ação inteligente (processo de adaptação), que procura relacionar as coisas ao pensamento, a assimilação ocorre num sentido mais experimental e a acomodação num

\footnotetext{
${ }^{7}$ Por objetos, devem-se entender “objetos de conhecimento”, genericamente. (García, 2002)
} 
sentido mais racional, promovendo as mudanças necessárias à estrutura de conhecimento pelo sujeito (PIAGET, 1971). A adaptação pode ser entendida como em estágio temporário de equilíbrio cognitivo, pois novas situações irão provocar o sujeito em direção a novas adaptações. A assimilação é sempre acompanhada de acomodação, mas nem sempre determinando um equilíbrio. Isto significa que o que se encontra nos processos de aprendizagem, muitas vezes, representa um predomínio da assimilação ou da acomodação. No que se refere à construção das estruturas, isso também se verifica. Por exemplo, no préoperatório, o jogo simbólico representa o predomínio da assimilação sobre a acomodação, e a imitação, o predomínio da acomodação sobre a assimilação.

Deve-se mencionar aqui o processo de equilibração. A equilibração atua no processo de adaptação em dois sentidos: fazendo mediação entre os novos dados e a situação atual do indivíduo bem como estabilizando esses processos a fim de mantê-los em interação e constante movimento (PIAGET 1971).

A equilibração "é a capacidade do sujeito de eliminar contradições e reestabelecer o equilíbrio precedente significando uma nova adaptação." (TEIXEIRA, 2008, p. 18). Para Piaget (1964), o processo de equilibração é fundamental para que haja desenvolvimento do indivíduo, visto que, para se alcançar níveis maiores de conhecimento, é necessário ter alçado o equilíbrio no nível imediatamente inferior e assim por diante, como em uma espiral integrativa em movimento ascendente. Neste sentido, pode-se entender o processo de equilibração como se constituindo de inúmeras adaptações e desadaptações, equilíbrios e desequilíbrios em direção ascendente e, portanto, majorante.

Como uma síntese dos processos de assimilação e acomodação, possibilitados e estabilizados pelo processo de equilibração, surge o processo inventivo, que está relacionado à aplicação de estratégias aos novos contextos por combinação mental.

\footnotetext{
...a invenção é comparável à «aplicação de meios conhecidos a novas situações», visto que, como nesta, procede por dedução; mas esta dedução, sendo criadora, participa também dos processos de aquisição que estudamos até agora e, singularmente, da descoberta de novos meios por experimentação activa (PIAGET, 1971, p. 345).
}

Reconhecendo a interação constante entre os processos aqui mencionados, parece mais adequado situar a invenção, para Piaget, como sendo impulsionada pelo processo de equilibração, por sua função mediadora entre os conhecimentos atuais e ideais do sujeito e, ao mesmo tempo, sendo interdependente dos processos de assimilação e acomodação.

De acordo com Pinto (2001), Piaget entende que a construção do conhecimento e o desenvolvimento cognitivo são desencadeados pela ação do sujeito. Tal processo, segundo 
Cohen e Kim (1999) se inicia quando o sujeito se depara com algo novo ou desconhecido, estranho às suas estruturas. É a partir da discrepância entre a necessidade e a própria realidade que um desequilíbrio cognitivo é gerado. Esse desequilíbrio ou conflito cognitivo pode ser visto como pivô do desenvolvimento de acordo com Stoltz (2008, p. 264) ao observar que "o sujeito constrói suas noções a partir das resistências que o meio lhe oferece."

Para Piaget (1971), há no comportamento humano uma tendência a uma procura experimental por novas assimilações, graças à coordenação dos esquemas, que possibilitam um comportamento de exploração do mundo real. A esse respeito, Piaget expressa:

\begin{abstract}
Mas a própria questão não será fruto da dissociação entre a necessidade e o ato na sua totalidade? Com efeito, as primeiras necessidades não existem antes dos ciclos motores que permitem satisfazê- las. Pelo contrário, aparecem durante o próprio funcionamento. Deste modo, não poderíamos dizer que precedem a repetição: elas também resultam dela, num ciclo sem fim (PIAGET, 1971, p. 58).

...o funcionamento dos órgãos gera, pela sua própria existência, uma necessidade psíquica sui generis, ou antes, uma série de necessidades vicariantes, cuja complexidade ultrapassa desde o início a simples satisfação orgânica. Para além disto, quanto mais a inteligência se desenvolve e se afirma, e quanto mais, a assimilação do real ao funcionamento próprio se transforma em compreensão real, mais a necessidade de incorporar as coisas aos esquemas do sujeito se torna o motor principal da atividade intelectual (PIAGET, 1971, p.59).
\end{abstract}

Percebe-se, então, que pelas próprias experiências do sujeito, surgem conflitos cognitivos os quais impulsionam o sujeito às explorações e deduções e esses, por sua vez, desencadearão os processos de assimilação e de acomodação num ciclo contínuo. De outra forma, pode-se dizer que, ao se deparar com o desconhecido, mesmo que empiricamente reconhecendo sua própria lacuna de conhecimento, o indivíduo pode agir para ultrapassá-la. Sendo esse o caso, o indivíduo pode realizar uma nova adaptação, a partir dos processos de assimilação e acomodação, dando continuidade aos ciclos de adaptações no desenvolvimento próprio da equilibração majorante.

De acordo com Piaget (1983, p. 224; PIAGET e INHELDER, 2007, 135-141), existem quatro fatores que, em interação mútua, determinam o desenvolvimento cognitivo humano: a) hereditariedade ou maturação interna (ou neurológica), referindo-se às características biológicas do ser humano que, por sua vez, interferem no desenvolvimento, sendo uma condição necessária para tal. Contudo, este fator, por si só, não é suficiente para explicar o desenvolvimento da cognição humana, pois é interdependente dos demais; b) experiência, ou seja, a atividade do indivíduo com o meio externo. Esse fator é explicado por Becker (2010) em dois sentidos: experiência física e experiência lógico-matemática, sendo a primeira relativa às experiências sensoriais do sujeito que, em interação, se apropria dos atributos do 
objeto a partir de uma abstração física. E a segunda, relacionada aos significados extraídos de tais experiências, envolvendo abstração reflexionante, refere-se às relações que não estão nos objetos, mas às que o sujeito faz entre eles. A abstração reflexionante envolve, em um primeiro momento, o reflexionamento a partir das coordenações das ações realizadas sobre o objeto e, em um segundo momento, a reflexão, que pode também ser entendida como uma coordenação das ações a partir do reflexionamento, ou de segundo grau ou tematização, possibilitando inúmeras generalizações. Cabe aqui destacar, ainda, a insuficiência de tal fator, mas também sua relevância, já que para Piaget, "é essencial agir sobre o objeto para conhecêlo" (TEIXEIRA, 2008, p. 18); c) interação e transmissão social, relativo às influências do meio externo sobre o sujeito e à importância do fator educativo no desenvolvimento. Esse fator ocorre a partir da linguagem e dos contextos educativos aos quais o indivíduo é exposto, mas também por si mesmo é insuficiente, pois como os processos de adaptação explicam, a aprendizagem depende sobretudo de construções individuais e não apenas de transmissão da conhecimentos e d) o processo de equilibração: é o fator que coordena os demais e determinante no desenvolvimento pois, segundo Cohen e Kim (1999), é um processo autorregulador que busca o próprio equilíbrio frente aos desafios do ambiente por meio do processo de adaptação. Em outras palavras, pode-se dizer que, na equilibração, o individuo reconstrói e reorganiza no plano intelectual as suas vivências como o resultado da integração entre os processos de maturação, experiência e transmissão social.

Dessa forma, pode-se dizer que, para Piaget (1964), o processo de aprendizagem ocorre por níveis gradativos, pois, é necessária a existência de estruturas prévias construídas por meio da adaptação do indivíduo (assimilação e acomodação, influenciados pelos quatro fatores de desenvolvimento) e da organização do que foi adaptado em um sistema coerente, por meio de um processo autorregulador (equilibração). O processo de aprendizagem depende, assim, sempre do desenvolvimento cognitivo.

No âmbito organizacional, Gilbert (2007) entende que muitos processos de solução de problemas tendem a ficar apenas no nível da assimilação, já que gerentes tendem a se satisfazer com análises feitas apenas com base naquilo que já se conhece ou já se teve experiência prévia. Segundo o autor, isso ocorre porque as pessoas conseguem identificar mais facilmente aquilo que faz sentido para elas, ou seja, relacionam novas informações àquelas que já possuem. Neste caso, não há criação de novos conhecimentos, visto que na assimilação se permanece no mesmo nível de desenvolvimento, não havendo modificação das estruturas internas. Para o autor, são os gerentes que normalmente não se satisfazem somente 
com as informações percebidas (ou percebíveis) que chegam ao nível da acomodação. Aqueles que não se conformam apenas com as informações visíveis e que buscam reestabelecer o equilíbrio com o ambiente logram mais sucesso em criar novos conhecimentos e, segundo Gilbert (2007), conseguem isto porque passam pelo processo de acomodação, reorganizando suas estruturas de conhecimento. Ainda para o autor, os meios pelos quais os indivíduos conseguem passar pelo processo de adaptação são pela experiência, ou seja, pela experimentação na prática daquilo que se pensa; pelo "ensaio mental" ou simulação mental e abstrata daquilo que está sendo tratado e pela confrontação intelectual, que se refere à discussão em grupo, conversas, etc. Para o autor, essas abordagens se contrapõem, muito embora seu maior ou menor uso dependa do funcionamento de cada indivíduo.

\section{EM DIREÇÃO ÀS APROXIMAÇÕES}

Partindo dos elementos apresentados, é possível passar para a discussão em torno das aproximações entre os teóricos tratados. Inicia-se tratando da principal, que está no entendimento de que a criação ou construção do conhecimento se dá pela interação e depende do conhecimento anterior para criar novos conhecimentos.

Para Nonaka e Takeuchi (1997), a criação do conhecimento acontece por meio da interação entre os conhecimentos tácito e explícito, na forma da espiral do conhecimento anteriormente apresentada. O modelo de criação de conhecimento desenvolvido por esses dois autores é representado por uma espiral contínua, que se amplia na medida em que os conhecimentos criados vão formando a base para possibilitar a criação de novos conhecimentos.

Da mesma forma, de acordo com Piaget, os processos de assimilação e acomodação, interligados à equilibração, são representados por uma espiral contínua, integrativa dos novos conhecimentos à estrutura, em movimento ascendente. Para Piaget (1964), o conhecimento também é construído a partir da interação que, neste caso, é a interação com objetos, entendidos como objetos de conhecimento. A interação fala de um sujeito que age sobre os objetos e de objetos que agem sobre ele, sendo a interação representativa do ponto de encontro. A lacuna entre o que o indivíduo sabe e aquilo que o objeto "oferece" ao indivíduo pode gerar um conflito cognitivo, que tende a desencadear o processo de equilibração. Esse processo parte sempre daquilo que já é conhecido do indivíduo, ou seja, a pessoa depende das 
estruturas de conhecimento já formadas para criar e internalizar novos conhecimentos.

Desse modo, enquanto que para Piaget o processo de equilibração pode ser desencadeado por um conflito cognitivo gerado pela interação do indivíduo com o objeto, para Nonaka e Takeuchi o processo de conversão do conhecimento é iniciado pelo modo de socialização, caracterizado pela interação entre indivíduos que compartilham conhecimento por meio do diálogo, da observação e troca de experiências. Assim, partindo do pressuposto de que nesse contexto de troca entre pessoas novos conhecimentos e pontos de vista distintos são "apresentados" aos indivíduos que interagem, o conflito cognitivo - como entendido por Piaget - pode ter terreno fértil para emergir. Isso significa dizer que é no modo de socialização, em que indivíduos compartilham conhecimentos tácitos, que o conflito cognitivo pode ser desencadeado dando início ao processo de adaptação, conforme visto na teoria piagetiana.

Sequencialmente, o modo de externalização surge à medida que os indivíduos passam a expressar seus conhecimentos tácitos (já existentes) de maneira sistematizada e inteligível para outras pessoas. Em seguida, parte-se para o compartilhamento desses conhecimentos explícitos, fase que é denominada modo de combinação. Analogamente, esses dois modos de conversão de conhecimento podem ser associados ao processo de assimilação entendido por Piaget. Nesse processo, os indivíduos não incorporam novos conhecimentos às suas estruturas, mas sim organizam o conhecimento existente - que antes era tácito e passou a ser explícito - o que lhes permite transmiti-lo mais facilmente a outras pessoas.

É apenas no modo de internalização, tratado por Nonaka e Takeuchi, que todo aquele conhecimento sistematizado, organizado e compartilhado poderá ser incorporado pelo indivíduo, na medida em que se aplica o conhecimento na prática e se aprende "fazendo", transformando-o em novos modelos mentais e know-how. Sob a ótica de Piaget, esse modo de conversão do conhecimento pode ser associado ao processo de acomodação, no qual as estruturas de conhecimento do sujeito são reorganizadas e em que pela assimilação e pela acomodação se chega ao conhecimento novo. Nesse caso, não é uma adição às estruturas prévias, mas uma modificação de toda a estrutura para acomodar ou incorporar esse novo conhecimento. Entende-se que é a partir desse momento que é possível dizer que o indivíduo passou de um nível de desenvolvimento para outro nível mais alto, quando a estrutura de conhecimento se expande com base nas estruturas anteriores, possibilitando novas aquisições num novo patamar de equilibração.

Em síntese, são apresentadas no Quadro 1 os aspectos tratados das teorias de Nonaka e 
Takeuchi e Jean Piaget, evidenciando-se proximidade entre as visões desses autores.

Quadro 1 - Aproximações teóricas entre Nonaka, Takeuchi e Piaget

\begin{tabular}{|c|c|c|}
\hline & Nonaka e Takeuchi & Piaget \\
\hline $\begin{array}{l}\text { Como ocorre o processo } \\
\text { de construção do } \\
\text { conhecimento }\end{array}$ & $\begin{array}{l}\text { Interações entre conhecimento tácito e } \\
\text { explícito. }\end{array}$ & $\begin{array}{l}\text { Interações com objetos*. } \\
(* \text { entende-se por objetos os objetos de } \\
\text { conhecimento })\end{array}$ \\
\hline $\begin{array}{l}\text { Como é explicado o } \\
\text { processo de construção } \\
\text { do conhecimento }\end{array}$ & $\begin{array}{l}\text { Espiral contínua, que se amplia à } \\
\text { medida que os conhecimentos criados } \\
\text { vão formando a base para possibilitar a } \\
\text { criação de novos conhecimentos. }\end{array}$ & $\begin{array}{l}\text { Espiral contínua, integrativa dos novos } \\
\text { conhecimentos à estrutura em movimento } \\
\text { ascendente (equilibração majorante) e } \\
\text { dependente dos fatores responsáveis pelo } \\
\text { desenvolvimento cognitivo: maturação, } \\
\text { experiência, interação e transmissão } \\
\text { social e processo de equilibração. }\end{array}$ \\
\hline $\begin{array}{l}\text { Início do processo de } \\
\text { construção do } \\
\text { conhecimento }\end{array}$ & 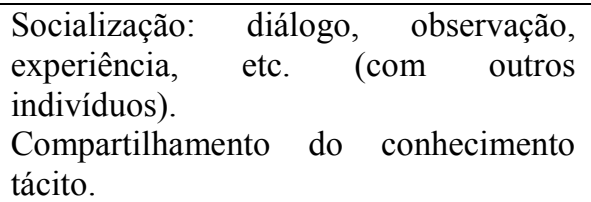 & $\begin{array}{l}\text { Assimilação e Conflito Cognitivo: quando } \\
\text { a interação com o objeto gera um conflito } \\
\text { - lançando um desafio para que o } \\
\text { indivíduo busque o conhecimento. }\end{array}$ \\
\hline \multirow[t]{2}{*}{$\begin{array}{l}\text { Interações com o } \\
\text { conhecimento explícito }\end{array}$} & 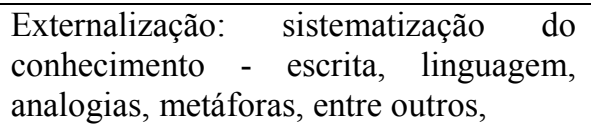 & \multirow{2}{*}{ 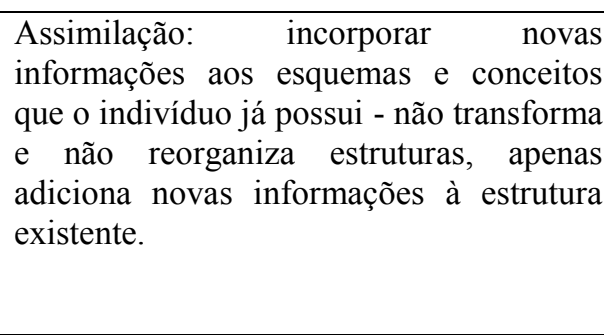 } \\
\hline & \begin{tabular}{llr} 
Combinação: & \multicolumn{2}{c}{ combinação } \\
conhecimentos & - pode gerar novas \\
classificações, & \multicolumn{2}{c}{ ordenamentos e } \\
categorizações & do conhecimento \\
explícito. & &
\end{tabular} & \\
\hline $\begin{array}{l}\text { "Absorção" do } \\
\text { conhecimento }\end{array}$ & $\begin{array}{llr}\text { Internalização: } & \text { incorporar } & \text { o } \\
\text { conhecimento } & \text { explícito } & \text { em } \\
\text { conhecimento tácito, que podem resultar } & \\
\text { em modelos mentais ou know-how }\end{array}$ & $\begin{array}{l}\text { Acomodação: gera modificações na } \\
\text { estrutura do sujeito - é a ação do } \\
\text { indivíduo modificando suas estruturas } \\
\text { para acomodar o novo conhecimento. É o } \\
\text { ajuste do sujeito ao objeto. Implica em } \\
\text { um nível maior de compreensão ou de } \\
\text { desenvolvimento. }\end{array}$ \\
\hline
\end{tabular}

Fonte: As autoras, com base em Nonaka e Takeuchi (1997) e Piaget (1964, 1983, 2007)

Entende-se, ainda, que outros elementos das teorias apresentadas podem ser relacionados. Já se tratou sobre como o conflito cognitivo pode desencadear o processo de busca por conhecimento na teoria piagetiana. E como, na teoria de Nonaka e Takeuchi, esse conflito pode emergir no modo de socialização. Contudo, é quando se estuda mais profundamente a teoria de Nonaka e Takeuchi que se entende que, ao promover um ambiente de Flutuação e Caos Criativo, o indivíduo tem mais chance de ser exposto a elementos que podem desencadear o conflito cognitivo. Os próprios autores afirmam que o objetivo de se promover a flutuação é que ela possa gerar um “'colapso' de rotinas, hábitos ou estruturas cognitivas" incentivando questionamentos sobre pensamentos e atitudes, promovendo a interação social, possibilitando a criação de novos conceitos (NONAKA e TAKEUCHI, 1997, p. 89). 
Além da Flutuação e Caos Criativos, Nonaka e Takeuchi defendem que a criação de conhecimento é facilitada também pela existência de Intenção, Autonomia, Redundância e Variedade de Requisitos. De forma geral, a existência desses fatores auxilia o processo de conversão de conhecimento à medida que aumenta a quantidade e diversidade de objetos de conhecimento a que cada indivíduo pode ter acesso, permitindo-lhes também autonomia de ação e direcionamento. Na teoria piagetiana, esses elementos podem ser considerados insumos para a criação de conhecimento, já que:

Conhecer um objeto, conhecer um acontecimento, não é simplesmente olhar para ele e fazer uma cópia ou imagem mental dele. Conhecer um objeto é agir sobre ele. Conhecer é modificar, transformar o objeto e entender o processo dessa transformação e, como uma consequência, entender como o objeto é construído. (PIAGET, 1964, p. 177).

Assim, quando mais objetos de conhecimento disponíveis e mais livremente o indivíduo for capaz de agir sobre ele, mais possibilidade ele tem de conhecê-lo.

As aproximações teóricas apresentadas entre os autores tratados abrangem aspectos relativos aos objetivos deste estudo, sem, contudo, esgotarem-se aqui. Apresentam-se, a seguir, as considerações finais do artigo e sugestões de novas investigações.

\section{CONSIDERAÇÕES FINAIS}

Ao apresentar alguns de seus conceitos fundamentais, buscou-se relacionar aspectos das teorias de Nonaka e Takeuchi e de Piaget no que se refere à construção do conhecimento e aos seus modos de conversão. Com foco no processo de equilibração de Piaget e nos modos de conversão do conhecimento de Nonaka e Takeuchi, o objetivo deste artigo é atendido na medida em que discute a possibilidade de aproximações entre esses teóricos.

Ao traçar tais comparações pretendeu-se enriquecer a teoria de criação do conhecimento organizacional, trazendo elementos da área da educação e da psicologia que possibilitem melhor entendimento e compreensão sobre os processos de criação do conhecimento desde o nível individual.

O processo de construção deste artigo possibilitou a percepção das teias de relações a partir da ação de refletir. A socialização, isto é, a explicitação das experiências na interação e o processo de exteriorização presente no diálogo ou pela reflexão fazem parte da construção coletiva de conhecimento criada no cotidiano das organizações de qualquer natureza. Esses processos geram ambientes interpretativos e interpretações individuais que servem de 
contexto e de guia para outras reflexões, questionamentos e passam a integrar o processo de transformação da realidade do contexto no qual os sujeitos estão inseridos. Além disso, o resultado das aproximações pode servir como ponto de partida para estudos posteriores que tenham como pano de fundo a pesquisa organizacional com contribuições de áreas afins.

\section{REFERÊNCIAS}

BECKER, F. Inteligência e Aprendizagem. Revista Educação. São Paulo, Edição Especial: História da Pedagogia - Jean Piaget, p.22 - 35, 2010.

BRINGUIER, J. C. Conversando com Jean Piaget. São Paulo: Difusão Editorial, 1978.

COHEN, L.M., KIM, Y.M. Piaget's equilibration theory and the young gifted child: a balancing act. Roeper Review, v. 21, n. 3, p. 201-204, fev/1999.

GARCÍA, A., FABREGAT, A. A construção humana através da equilibração de estruturas cognitivas: Jean Piaget. In: Minguet, P.A. (Org). A construção do conhecimento na educação. Porto Alegre: Artmed, 1998.

GILBERT, X. Globalizing local knowledge in global companies. In: ICHIJO, K.; NONAKA, I. (Org.) Knowledge creation and management: new challenges for managers. New York: Oxford University Press, 2007. KESSELRING, T. Jean Piaget. Caxias do Sul: Educs, 2008.

NONAKA, I.; TAKEUCHI, H. Criação de conhecimento da empresa: como as organizações japonesas geram a dinâmica da inovação. Rio de Janeiro: Campus, 1997.

NONAKA, I. A Dynamic Theory of Organizational Knowledge Creation. Organization Science, v. 5, n. 1, p. 14-37, fev/1994.

NUNES, L. D. Aprendizagem por conflito sócio-cognitivo e abertura de possíveis. 185f. Dissertação (Mestrado em Educação) - Setor de Educação, Universidade Estadual de Campinas, Campinas, 1998.

PIAGET, J. Coleção Os Pensadores. 2. ed. São Paulo: Abril Cultural, 1983. 296 p. (A epistemologia genética / Sabedoria e ilusões da filosifia / Problemas de psicologia genética)

PIAGET, J. Development and learning. Journal of Research in Science Teaching, v. 11, n. 3, p. 176-186, 1964.

PIAGET, J. O estruturalismo. 3. ed. Rio de Janeiro: Difel, 1979.

PIAGET, J. O nascimento da inteligência na criança. Lisboa: Dom Quixote, 1986.

PIAGET, J. O Nascimento da Inteligência na Criança. Lisboa Codex, Portugal, 1971. 
PIAGET, J., INHELDER, B. A psicologia da criança. 3. ed. Rio de Janeiro: Difel, 2007.

PINTO, A. M. A importância das contribuições de Piaget e Polanyi em Gestão do Conhecimento e Aproximações na perspectiva Organizacional. In: SEMINÁRIO CATARINENSE DE GESTÃO DO CONHECIMENTO E DA TECNOLOGIA, 2001, Florianópolis. Anais..., 2001.

SILVA, M. C. Piaget, Vygotsky, Paulo Freire e Feuerstein: aproximações téorico-conceituais. PsicoGlobal, Portugal, v. 184, p. 1-19, 2008. Disponível em: $<$ http://www.psicologia.com.pt/artigos/textos/A0414.pdf>. Acesso em: 16/04/2009.

STOLTZ, T. A informação e a organização da informação no conhecimento social. In: GUimarães. S. R. K. ; STOLTZ, T. (Orgs.) Tomada de Consciência e conhecimento metacognitivo. Curitiba: Editora UFPR, 2008. p. 263 -278.

TEIXEIRA, M. Interação social e tomada de consciência a partir do desenho de adultos. 284f. Dissertação (Mestrado em Educação) - Setor de Educação, Universidade Federal do Paraná, Curitiba, 2008. 